\title{
PULMONARY FUNCTION IN DIAPHRAGMATIC PARALYSIS
}

BY

\author{
MICHAEL MCCREDIE,* FRANK W. LOVEJOY Jr., AND NOLAN L. KALTREIDER \\ From the Cardiopulmonary Laboratory of the Department of Medicine, University of Rochester \\ School of Medicine and Dentistry, and the Medical Clinics of Strong Memorial and Rochester \\ Municipal Hospitals, Rochester, New York
}

(RECEIVED FOR PUbliCATION DECEMBER 6, 1961)

Orthopnoea as an outstanding symptom in weakness of the respiratory muscles was reported by Comroe, Wood, Kay and Spoont in 1951. We have had the opportunity of studying three patients with diaphragmatic paralysis from different causes, and orthopnoea was the chief complaint in all three.

Paralysis or weakness of respiratory muscles is probably seen most commonly in poliomyelitis, when there is usually involvement of diaphragms and intercostal nerves. In the three cases reported here, the diaphragm was affected exclusively in one; in the other two, although some weakness of intercostal nerves could not be excluded, there was objective evidence of diaphragmatic weakness only.

\section{MethodS}

All three patients were studied in the sitting position. Arterial blood samples were obtained in the supine posture, and in each an additional vital capacity measurement was recorded supine. 'Supine' studies in the first patient were done with him lying on his side at an angle of $20^{\circ}$ as he was unable to tolerate the horizontal position. All were studied again after intervals of from four months to two years.

Lung volumes were measured by a modification of the helium dilution method of Meneely and Kaltreider (1949), and all volumes were corrected to B.T.P.S. Airway resistance and thoracic gas volume $\left(F R C_{\text {Box }}\right)$ were measured by the plethysmographic method of DuBois, Botelho, Bedell, Marshall, and Comroe (1956). The maximal midinspiratory and mid-expiratory flow rates and first second forced expiratory volume were calculated from a record of a forced expiratory vital capacity from a Krogh spirometer (Leuallen and Fowler, 1955). Nitrogen washout from $750 \mathrm{ml}$. to $1,250 \mathrm{ml}$. of the same forced expirate was recorded from a nitrogen meter with the sampling needle placed

*In receipt of a Wellcome research travel grant. just outside the mouth (Comroe and Fowler, 1951). Both the forced expiratory volume and nitrogen concentration were recorded on a Sanborn Polyviso at a paper speed of $2.5 \mathrm{~cm}$. per second. Diffusing capacity for carbon monoxide was estimated using the single breath method of Ogilvie, Forster, Blakemore, and Morton (1957). Compliance in patients 2 and 3 was calculated from simultaneous recordings on the Sanborn Polyviso of tidal volume and intrathoracic pressure changes. The volume of air flow was recorded from the output of a potentiometer attached to the pulley wheel of a Benedict-Roth spirometer. The effective intrathoracic pressure was taken as the pressure difference between the mouth and the lumen of the oesophageal balloon.

Arterial blood was analysed for $\mathrm{O}_{2}$ and $\mathrm{CO}_{2}$ contents by the manometric method of Van Slyke and Neill (1924). Before December, 1960, $\mathrm{PaCO}_{2}$ was measured by the Riley bubble technique; since December, 1960, $\mathrm{PaCO}_{2}$ has been measured by means of a Severinghaus $\mathrm{CO}_{2}$ electrode (Severinghaus, Stupfel, and Bradley, 1956).

\section{CASE RePorts}

PATIENT 1 (J. R.).-This 45-year-old patrolman first presented to his physician in May, 1960, complaining of pain and paraesthesiae down both arms, and for this he underwent bilateral scalenus anterior section at another hospital on September 13, 1960. At operation he developed severe respiratory distress as soon as the second side was sectioned, and he became deeply cyanosed and required assisted breathing. On recovering from the anaesthetic, he was unable to breathe and had to be placed in an artificial respirator.

For the next 48 hours his condition did not improve; his respiratory distress was increased by copious bronchial secretions which were aspirated with difficulty. $\mathrm{He}$ was described as an acutely anxious man who could not keep his own attempted respiratory movements in time with those of the respirator.

He was transferred to Strong Memorial Hospital on September 16, 1960, and treated with positive 
TABLE I

SUMMARY OF PULMONARY FUNCTION TESTS

\begin{tabular}{|c|c|c|c|c|c|c|c|c|}
\hline & Patient 1 & & & Patient 2 & & & Patient & \\
\hline 26960 & $7 / 261$ & Predicted $\dagger$ & 13961 & 31161 & Predicted $\dagger$ & 20259 & 3861 & Predicted \\
\hline $\begin{array}{l}1.96 \\
0.80\end{array}$ & $\begin{array}{l}2.25 \\
1.49\end{array}$ & $3 \cdot 71$ & $\begin{array}{l}2.07 \\
0.80\end{array}$ & $2 \cdot 15$ & $3 \cdot 78$ & 1.67 & $\begin{array}{l}2.28 \\
1.24\end{array}$ & $3 \cdot 85$ \\
\hline 0.82 & 0.66 & & 0.73 & $0 \cdot 70$ & & $0 \cdot 38$ & 0.53 & \\
\hline $2 \cdot 39$ & $2 \cdot 40$ & & $2 \cdot 36$ & $2 \cdot 34$ & & $2 \cdot 08$ & 1.91 & \\
\hline $1 \cdot 58$ & $1 \cdot 74$ & $1 \cdot 14$ & 1.66 & 1.64 & $1 \cdot 15$ & $1 \cdot 70$ & $1 \cdot 39$ & $1 \cdot 71$ \\
\hline $3 \cdot 53$ & 3.99 & $4 \cdot 85$ & $3 \cdot 73$ & 3.79 & 4.93 & $3 \cdot 37$ & 3.68 & $5 \cdot 56$ \\
\hline $44 \cdot 6$ & 43.6 & $23 \cdot 4$ & $44 \cdot 5$ & $43 \cdot 2$ & $23 \cdot 4$ & 50 & $37 \cdot 8$ & $30 \cdot 8$ \\
\hline $2 \cdot 58$ & 2.05 & $7.06 \pm 1.02$ & $2 \cdot 20$ & 1.83 & $7.06 \pm 1.02$ & & $2 \cdot 19$ & $7 \cdot 06 \pm 1.02$ \\
\hline $2 \cdot 88$ & $2 \cdot 65$ & $4 \cdot 37 \pm 1 \cdot 1$ & 0.81 & 0.83 & $4 \cdot 37 \doteqdot 1 \cdot 1$ & & $1 \cdot 24$ & $3.71+1.00$ \\
\hline 87 & 87 & 75 & 68 & 70 & 75 & 69 & 76 & 75 \\
\hline & $2 \cdot 63$ & & 3.06 & $3 \cdot 32$ & & & $3 \cdot 13$ & \\
\hline ) & 1.4 & $<2.5$ & $4 \cdot 2$ & $4 \cdot 3$ & $<2.5$ & $3 \cdot 3$ & $2 \cdot 6$ & $<2 \cdot 5$ \\
\hline $18 \cdot 5$ & $20 \cdot 4$ & $>17$ & $14 \cdot 7$ & $12 \cdot 3$ & $>17$ & $24 \cdot 2$ & $20 \cdot 7$ & $>17$ \\
\hline & & & $0 \cdot 29$ & & & $0 \cdot 13$ & & \\
\hline $0 \cdot 5$ & $1 \cdot 5$ & $<1.5$ & & $1 \cdot 6$ & $<1.5$ & & $2 \cdot 0$ & $<1.5$ \\
\hline $\begin{array}{l}94 \cdot 2 \\
91 \cdot 5\end{array}$ & $\begin{array}{l}94 \cdot 5 \\
94 \cdot 0\end{array}$ & & $\begin{array}{l}90 \\
86 \cdot 7\end{array}$ & $\begin{array}{l}88.4 \\
85.3 \\
80 \cdot 6\end{array}$ & & $99 \cdot 1$ & $\begin{array}{l}91 \cdot 8 \\
92 \cdot 5\end{array}$ & \\
\hline $\begin{array}{l}39 \\
40\end{array}$ & $\begin{array}{l}41 \\
42\end{array}$ & & $\begin{array}{l}40 \\
42\end{array}$ & 45 & & 44 & $\begin{array}{l}37 \\
40\end{array}$ & \\
\hline
\end{tabular}

* Lung volumes estimated by helium dilution method: $\max$. mid-IFR and max. mid-EFR = maximum mid-inspiratory and mid-expiratory flow rates; F.E.V. = first second timed vital capacity; FRCBox = functional residual capacity estimated by whole body plethysmograph; DLCo $=$ diffusing capacity for carbon monoxide; $\mathrm{N}_{2}$ washout = percentage rise in nitrogen concentration between $750 \mathrm{ml}$. and $1,250 \mathrm{ml}$. of expired air.

+ Predicted values for lung volumes taken from the data of Baldwin, Cournand, and Richards (1948); for maximum mid-EFR and F.E. from the data of Leuallen and Fowler (1955); those for maximum mid-IFR, airway resistance, diffusing capacity, and nitrogen washout are from observed data for this laboratory.

pressure respiration, oxygen, and sedation. From that time his condition improved. After a further $4 \delta$ hours he was able to breathe for himself in the erect posture, but he was unable to lie down because of severe orthopnoea. He stated that he had difficulty breathing in rather than out.

Over the next week his condition steadily improved. and he was referred for pulmonary function studies. On examination at this time he was a stocky man with an anxious face. There was no cyanosis and no clubbing. Chest movements were equal, but there was poor expansion and absent breath sounds at the bases. On lying down he immediately developed severe respiratory difficulty and became very agitated.

A chest radiograph showed a high diaphragm on both sides, some fluid at both bases, and some basal atelectasis. On fluoroscopy the diaphragm moved down only about $1 \mathrm{~cm}$. on each side with inspiration. He was quite unable to lie flat, and 'supine' studies were done with the patient lying at an angle of $20^{\circ}$ on his side. Results of pulmonary function tests are shown in Table I.

He was seen again on February 7, 1961, and was considerably improved but he still had mild dyspnoea and fatigue on exertion and mild orthopnoea. On fluoroscopy the left diaphragm moved down $2 \mathrm{~cm}$. 0.7 inspiration. The right diaphragm was immobile.

PATIENT 2 (L. I.).-A 47-year-old stationary engineer had an injection of anti-tetanus serum after an injury with a nail to the left elbow in May, 1960. One week after this he noted the sudden onset of tightening of the elbow and chest muscles, dyspnoea with orthopnoea. fever. and joint pains. particularly in both shoulders. The fever and joint and muscle symptoms disappeared after two weeks, but the dyspnoea on effort with orthopnoea persisted and was associated with cough productive of a little watery sputum.

His chief complaint when seen on September 13. 1960, was of orthopnoea. Breathing was normal when sitting at rest, but within 10 seconds of lying flat he developed severe respiratory distress. He stated that the difficulty was mainly inspiratory; he had little difficulty breathing out, but could not breathe in adequately while lying down. The severity of the orthopnoea varied somewhat during the day and was worse after meals. He had also noticed dyspnoe 1 while lifting a case held against the abdomen. At best, he could tolerate the supine position for about three minutes, at worst for only 10 seconds.

He had a past history of 'sinus trouble' for 18 years, and 15 years ago was told by a doctor that he had a 'touch of asthma,' but he had never noticed any wheezing and had no history of allergy. He had had at least two other injections of anti-tetanus serum. one within two years.

On examination he was a well-built man in no respiratory distress sitting at rest. There was no clubbing and no detectable cyanosis. Chest expansion was normal and equal on both sides, but clinically diaphragmatic movement appeared limited. Breath 
sounds were normal, and there were no wheezes or crepitations. There was a small healed area on the left elbow where the nail had entered, overlying the olecranon bursa, which was filled with fluid but not tender. He had weakness of the left deltoid muscle but no other abnormalities on physical examination. A chest radiograph showed a high diaphragm on both sides at the level of the seventh rib on the left and the ninth rib on the right, with blunting of the left costophrenic angle. On fluoroscopy the diaphragm moved with the chest wall on inspiration. There was no significant independent movement of the diaphragm, and the slight detectable movement, if any, was paradoxical.

In the supine position, the right side moved up $2 \mathrm{~cm}$. on inspiration and the left one was immobile. Pulmonary function studies showed diminished vital capacity, marked airway obstruction, arterial desaturation with a normal $\mathrm{PaCO}_{2}$ and a low diffusing capacity (see Table I).

He was seen again on January 31,1961 , and, although he was somewhat improved, he still had moderate dyspnoea on effort and marked orthopnoea. The chest film showed no change, but on fluoroscopy the left diaphragm was quite immobile; the right one moved down $1 \mathrm{~cm}$. on inspiration when tilted at $20^{\circ}$ but moved paradoxically when flat. There was no significant change in any of the pulmonary function studies.

Patient 3 (L. B.).-This 54-year-old white man suddenly developed acute respiratory distress while in bed on the night of February 8, 1959. He noticed almost complete relief when sitting up straight, standing, or walking, but could not go more than $45^{\circ}$ toward the supine position without becoming markedly short of breath.

There was no previous history of pulmonary disease, and he had no cough or wheezing. He had a long history of arthritis involving multiple joints including spine, shoulders, knees, and ankles. This had been treated with steroids until a week before admission on February 8, 1959, to another hospital, when he developed a stubborn gastroenteritis, and steroids were discontinued. The gastroenteritis, which cleared up two days before the onset of acute orthopnoea, was treated with tetracycline and antispasmodics. There was no history of antecedent respiratory infection.

$\mathrm{He}$ was said to be acutely anxious at that time. Although his anxiety decreased with sedation, this did not alleviate his acute respiratory distress on approaching the supine position, and he received no benefit from oxygen. He had a history of somewhat similar episodes in the past, although not nearly so severe and always transient, and he denied any dyspnoea apart from these episodes.

On February 20, 1959, he was admitted to Strong Memorial Hospital. On examination he was rather anxious, and there was no cyanosis or clubbing. On lying flat he immediately developed respiratory distress. The antero-posterior diameter of the chest was increased, with elevated diaphragmatic dullness and decreased breath sounds at the bases. Wheezing and crepitations were absent, and the heart sounds were normal. There was no evidence of cardiac failure.

The arthritic changes were degenerative in type and involved mainly the knees, ankles, shoulders, and cervical spine. Clinically, there was no gross involvement of the thoracic spine. There were no other abnormal physical findings.

A chest radiograph showed the right diaphragm at the level of the seventh rib, the left diaphragm at the level of the eighth rib posteriorly, and clear lung fields. There was some cardiac enlargement and unfolding of the aorta. Films of the cervical spine showed narrowing of the disc spaces C5 to $\mathrm{C} 6$ and C6 to $\mathrm{C} 7$ with spur formation anteriorly. On fluoroscopy, diaphragmatic movement was irregular, and on occasion the diaphragm moved up on inspiration and sniff testing. On reclining, the diaphragm ascended to the fifth rib level on both sides. An electrocardiogram showed some flattening of the $T$ waves in the left ventricular leads.

Pulmonary function tests showed reduced vital capacity, high RV/TC ratio, and mild airway obstruction (see Table I). Because of the suspicion that the orthopnoea might have been psychogenic in origin, some of the tests were repeated under hypnosis without appreciable change.

He was seen again on March 8, 1961. The orthopnoea had gradually improved over the two years and was now very mild; he could sleep on his side comfortably with two pillows. The arthritis had become worse, however. The chest radiograph showed both diaphragms at the level of the ninth rib posteriorly and enlargement of the heart and ascending aorta. On fluoroscopy in the supine position the right diaphragm moved down $2 \mathrm{~cm}$. on inspiration and the left one moved hardly at all. The electrocardiogram was unchanged.

\section{COMMENTS}

Aetiology.-The first case seems to be clearly related to surgical trauma and is of particular interest because it demonstrates the picture of pure phrenic paralysis uncomplicated by preexisting pulmonary or other systemic disease. The fact that he showed partial recovery over a period of five months suggests that the phrenic nerves had not been completely sectioned.

The second case appeared to be definitely related to the antitetanus serum, and the condition was almost certainly part of a serum reaction, as was that of the case reported by Comroe et al. (1951). Peripheral neuropathy is a well-known complication of antitetanus serum (Doyle, 1933) and is usually confined to nerves arising from the cervical cord. Since antitetanus serum is usually injected into the deltoid region, this suggests that 
it is a specific local neuritic reaction. The nerves most commonly involved are those from the brachial plexus, especially the nerve to the deltoid, and the recurrent laryngeal nerve. Weakness of the muscles of respiration is rare, and generalized peripheral neuropathy has been reported (Richardson, 1917).

Most of the cases of motor neuritis reported following the injection of antitetanus serum have cleared up in about two months, but they may last up to two years (Comroe et al., 1951). Our patient showed no objective improvement over a period of nine months except for some recovery of movement of the right diaphragm, but recovery of phrenic nerve function may have been obscured, at least in part, by underlying pulmonary disease.

The cause of the phrenic paralysis in the third man is unknown. It may possibly have been on an infective basis related to the preceding gastroenteritis. It seems unlikely that his respiratory distress was related directly to arthritic involvement of the thoracic spine, as clinically movements of the thoracic spine were free, and the chest cage expanded normally. There were, however, marked degenerative changes in the cervical spine, and it is possible that the phrenic nerves were involved in this process at the spinal root level.

Pulmonary Function.-The first patient is of particular interest because he demonstrates the clinical and functional picture of pure diaphragmatic paralysis. The pulmonary function tests are listed in Table I, and the main features in the first patient are reduction of vital capacity, which was still further reduced in the supine position ; normal functional residual capacity (F.R.C.), diminished expiratory reserve volume, and hence increase in residual volume and RV/TC ratio; no evidence of airway obstruction or of gas trapping ; normal diffusion; normal distribution of ventilation; arterial saturation normal in the erect posture but slightly reduced in the supine position.

All three patients had a vital capacity reduced to about half their predicted value in the erect posture, and this was further reduced in the supine position. Functional residual capacity was normal in all, and the expiratory reserve volume was small in all. It is likely that the apparent increase in residual volume in the first and second patients was not due to hyperinflated lungs. The high $\mathrm{RV} / \mathrm{TC}$ ratio was due to the reduced vital capacity plus the factors discussed above, and in no case does it indicate emphysema.
All three patients had a maximal mid-inspiratory flow rate which was significantly less than normal. The maximal mid-expiratory flow rate was normal in patient 1 (and, in fact, faster than mid-inspiratory flow rate) and reduced in patients 2 and 3 , who also had other evidence of airway obstruction. In the third patient this was only moderate and may have been due to bronchial narrowing due to elevation of the diaphragm, since two years later, with improvement in diaphragmatic function, airway resistance was almost normal. In patient 2 there was active bronchospasm in addition, since the airway resistance fell to normal with inhalation of a bronchodilator aerosol. It is interesting to note the discrepancy between the one-second timed (F.E.V..$_{1}$ ) vital capacity, which was nearly normal in both patients, and mid-expiratory flow rate and airway resistance. This finding of a normal F.E.V. in patients with definite airway obstruction and small vital capacity has been noted before (Lovejoy and Constantine, 1961). It seems likely that the second patient had been unconsciously dealing with increased airway resistance for years, but all three noticed the difficulty with inspiration, on the basis of diaphragmatic weakness, because of its recent onset. These findings support theio complaint that the difficulty was chiefly with inspiration. The patient who complains that it is difficult to breathe in is frequently neurotic, and it is important to note this mechanism as a real organic basis for this symptom.

Arterial $\mathrm{O}_{2}$ saturation showed a small but probably significant drop in the supine position in patients 1 and 2 . Arterial blood was not obtained from the third patient in the supine position when first seen. Patient 2 was desaturated at rest in the erect posture also, and it seems likely that he had a significant volume of perfused but poorly ventilated lung, probably due to the high diaphragm. Reduction in ventilated lung volume would also explain the low diffusing capacity for carbon monoxide. On the basis of this argument, these findings in patient 2 probably indicate more severe affection rather than a different mechanism.

ORTHOPNOEA.-The symptom of orthopnoea is worthy of discussion. It seems clear enough that the fundamental cause of the respiratory difficulty in the supine position is due to increased pressure of abdominal contents on the weakened diaphragm, as well as increased stiffness of the lungs in the supine position producing increased work of breathing. Present evidence indicates that this is the chief mechanism for producing orthopnoea in patients with cardiac disease (Altschule, 1949; Christie and Meakins, 1934), and although there 
was no evidence of cardiac failure in any of our patients, the mechanism is probably similar.

Elevation of the diaphragm in recumbency results in a decrease in functional residual capacity (Christie and McIntosh, 1934). Cherniack, Cuddy, and Armstrong (1957) have shown that there is an increase in both elastic and viscous resistance in orthopnoeic cardiac patients on adopting the recumbent position, the increase in viscous resistance being relatively much greater. They related their latter finding to low lung volumes in the recumbent position. We did not measure F.R.C. in the supine position, but there was gross elevation of both diaphragms on fluoroscopy in patients 2 and 3, and we can infer that the F.R.C. was diminished. Mechanical studies on the third patient were done in the sitting position and when recumbent at an angle of $35^{\circ}$; there was a fourfold decrease in compliance in the latter position and corresponding increase in both elastic and viscous resistance and work of breathing. This evidence supports the contention that elevation of the diaphragm increases the stiffness of the lungs and the work of breathing, and the diminution of lung volume contributes to the increase in nonelastic resistance and work of breathing in the recumbent position.

Knowles, Hong, and Rahn (1959) have pointed out the possible errors in measuring compliance in the supine position. They found that when compliance was measured in the prone position there was no demonstrable change between the erect and horizontal posture in normal subjects. They inferred that the weight of the heart and mediastinum may influence the intraoesophageal pressure and give falsely low values for compliance. In the light of this very important finding, studies on the mechanical properties of the lungs in congestive heart failure need to be re-evaluated. It may be that the impaired efficiency of the diaphragm as an inspiratory muscle against the increased pressure from abdominal contents in the horizontal position may be the factor chiefly responsible for the symptom of orthopnoea in these patients.

A small but significant drop in arterial oxygen saturation from the sitting to the recumbent position was demonstrated in the presence of orthopnoea in patients 1 and 2 . There was no change in saturation in patients 1 and 3 after orthopnoea had subsided and diaphragmatic function had improved. Thus, anoxaemia, which was presumably due to alteration of ventilation-perfusion ratios in part of the lungs, may have been a contributing factor but was not alone sufficient to cause orthopnoea. There was no significant rise in $\mathrm{PaCO}_{2}$ in any patient ; hence the anoxaemia was not due to hypoventilation, nor was hypercapnoea responsible for the respiratory stimulus.

\section{SUMmary}

Three patients with diaphragmatic paralysis are reported, and results of pulmonary function tests are presented.

Impairment of diaphragmatic function produces a pattern of pulmonary dysfunction characterized by diminution in vital capacity in the erect posture and, if dyspnoea is present, the difficulty is chiefly with inspiration.

Orthopnoea is the outstanding symptom in these patients. In the recumbent position vital capacity is still further reduced, and there may be a fall in arterial oxygen saturation. Orthopnoea is caused by elevation of the diaphragm in the supine position, which leads to decrease in lung volume and increased stiffness of the lungs, together with the mechanical inefficiency of the diaphragm as a muscle of inspiration against the increased pressure of abdominal contents in this position. Anoxaemia may be a contributory factor, and alveolar hypoventilation and hypercapnoea did not occur.

This study was supported in part by a research grant-in-aid, RG-7284, from the U.S. Public Health Service, and by a grant from the Heart Committee of the Health Association of Rochester and Monroe County.

\section{REFERENCES}

Altschule, M. D. (1949). Phvsiology in Diseases of the Heart and Lungs, p. 175. Harvard University Press, Cambridge, Mass.

Baldwin, E. de F., Cournand. A., and Richards, D. W. Jr. (1948). Medicine (Baltimore), 27, 243.

Cherniack, R. M.. Cuddy, T. E., and Armstrong, J. B. (1957). Circulation, 15, 859 .

Christie, R. V.. and McIntosh, C. A. (1934). J. clin. Invest., 13, 279. - and Meakins, J. C. (1934). Ibid., 13, 323.

Comroe, J. H. Jr., and Fowler, W. S. (1951). Amer. J. Med., 10, 408. ,Wood, F. C., Kay, C. F., and Spoont, E. M. (1951). Ibid., 10, 786 .

Doyle, J. B. (1933). Amer. J. med. Sci., 185, 484.

DuBois, A. B., Botelho, S. Y., Bedell, G. N., Marshall, R., and Comroe, J. H., Jr. (1956). J. clin. Invest., 35, 322.

- - and Comroe, J. H., Jr. (1956). Ibid., 35, 327.

Knowles, J. H., Hong, S. K., and Rahn, H. (1959). J. appl. Physicl.. $14,525$. Leuallen, E. C., and Fowler, W. S. (1955). Amer. Rev. Tuberc., 72,
783 .

Lovejoy, F. W.. Jr., and Constantine, H. (1961). Amer. Rev. resp. Dis., 84, 134.

Meneely, G. R., and Kaltreider, N. L. (1949). J. clin. Invest., 28, 129. Ogilvie. C M.. Forster, R. E., Blakemore, W. S., and Morton, J. W. (1957). Ibid., 36, 1.

Richardson, W. W. (1917). J. Amer. med. Ass., 68, 1611.

Severinghaus, J. W., Stupfel, M., and Bradley, A. F.(1956). J. appl Physiol., 9, 189.

Van Slyke, D. D., and Neill, J. M. (1924). J. biol. Chem., 61, 523. 